\title{
Mini-laparoscopy, laparoendoscopic single-site surgery and natural orifice transluminal endoscopic surgery-assisted laparoscopy: novice surgeons' performance and perception in a porcine nephrectomy model
}

\author{
Riccardo Autorino ${ }^{1,5}$, Fernando J. Kim ${ }^{6}$, Jens Rassweiler ${ }^{7}$, Marco De Sio ${ }^{1}$, \\ Maria J. Ribal ${ }^{8}$, Evangelos Liatsikos ${ }^{9}$, Rocco Damiano ${ }^{2}$, Luca Cindolo ${ }^{3}$, \\ Pierluigi Bove ${ }^{4}$, Luigi Schips ${ }^{3}$, Abhay Rané ${ }^{10}$, Carmelo Quattrone ${ }^{1}$, \\ Jorge Correia-Pinto ${ }^{11,12}$ and Estevão Lima ${ }^{11,13}$ \\ ${ }^{1}$ Urology Clinic, Second University of Naples, Naples, ${ }^{2}$ Urology Unit, Magna Graecia University, Catanzaro, ${ }^{3}$ S. Pio \\ da Pietralcina Hospital, Vasto, ${ }^{4}$ Dept of Urology, Tor Vergata University, Rome, Italy, ${ }^{5} \mathrm{Glickman}$ Urological and \\ Kidney Institute, Cleveland Clinic, Cleveland, $\mathrm{OH}_{1}^{6}$ Denver Health Medical Center, University of Colorado Health \\ Science Center, Denver, CO, USA, 'Department of Urology, Klinikum Heilbronn, University of Heidelberg, Heidelberg, \\ Germany, ${ }^{8}$ Department of Urology, Hospital Clinic, Barcelona, Spain, ${ }^{9}$ Department of Urology, University of Patras, \\ School of Medicine, Patras, Greece, ${ }^{10}$ Department of Urology, East Surrey Hospital, Redhill, UK, "School of Health \\ Sciences, University of Minho, Braga, ${ }^{12}$ Department of Pediatric Surgery, Hospital of Braga, Braga, and \\ ${ }^{13}$ Department of Urology, Hospital of Braga, Braga, Portugal \\ Accepted for publication 23 March 2012
}

Study Type - Therapy (case series) Level of Evidence 4

\section{OBJECTIVE}

- To evaluate the perception and performance of urological surgeons when first applying scarless surgical techniques.

\section{METHODS}

- The study was conducted during the $2^{\text {nd }}$ Minimally Invasive Urological Surgical Week annual course in Braga, Portugal.

- Fourteen attendees performed three porcine nephrectomies by using each of the following techniques: mini-laparoscopy, laparoendoscopic single-site surgery (LESS) and natural orifice transluminal endoscopic surgery (NOTES)-assisted laparoscopy.

- Peri-operative data were recorded, and operating performance was scored by one experienced surgeon for each working station, using a global rating scale.

- The surgeons' subjective perceptions of degree of difficulty were graded and their expectations before the procedures were recorded.

What's known on the subject? and What does the study add?

Over the last few years, minimally invasive urological surgery has evolved towards less invasive, 'scarless' procedures. New surgical concepts, such as those of natural orifice transluminal endoscopic surgery (NOTES) and laparoendoscopic single-site surgery (LESS) have been introduced. Mini-laparoscopy has been rediscovered in an attempt to reduce the invasiveness of standard laparoscopy.

This study is the first to compare the perception of surgeons when first facing three different scarless options for performing a porcine nephrectomy and when dealing with the constraints of each technique. The study findings suggest that: (i) when first approaching these techniques, surgeons tend to perform equally well under expert guidance in the porcine model; (ii) mini-laparoscopy is perceived as less difficult to perform; (iii) for all the techniques, surgeon's impressions are in line with their expectations.

\section{RESULTS}

- Forty-two porcine nephrectomies were performed.

- There were no differences in overall operating time, or time to dissect and manage the renal vascular hilum, whereas time to gain access was faster for LESS than for mini-laparoscopy or NOTESassisted laparoscopy (mean [SD] 8 [6] min vs 10.2 [5.3] $\mathrm{min}$ vs 9.9 [5.3] $\mathrm{min}$, respectively; $P=0.59$ ).

- A better visualization of the surgical field was obtained with mini-laparoscopy and there was a higher degree of difficulty of bimanual dexterity for LESS, but no significant differences were found among the three techniques for any variable (operating field view: $P=0.52$; bimanual dexterity: $P=0.49$; efficiency: $P=0.77$; tissue handling: $P=0.61$; autonomy: $P=0.2$ ).

- Subjective perception of the degree of difficulty trended in favour of minilaparoscopy $(P=0.17)$, but no significant difference was found in terms of surgeons' impression as compared with their expectations $(P=0.34)$. 


\section{CONCLUSIONS}

- When first approaching new scarless techniques, surgeons tend to perform equally well under expert guidance in the porcine model.
- Mini-laparoscopy is perceived as less difficult to perform and, for all the techniques, surgeons' impressions are in line with their expectations.

\section{KEYWORDS}

laparoendoscopic single site surgery, LESS, mini-laparoscopy, natural orifice translumenal endoscopic surgery, NOTES, perception, scarless surgery, single-port laparoscopy, training

\section{INTRODUCTION}

Over the last few years, minimally invasive urological surgery has evolved towards less invasive, 'scarless' procedures. New surgical techniques, such as natural orifice transluminal endoscopic surgery (NOTES) and laparoendoscopic single-site surgery (LESS) have been introduced $[1,2]$. Numerous hurdles still prevent a broad clinical translation of NOTES [2] and at this time, hybrid NOTES or NOTES-assisted laparoscopic techniques seem to be more ready for use in clinical practice $[3,4]$. LESS has been increasingly adopted worldwide, in urology as well as in other surgical specialties $[5,6]$. Nevertheless, the claimed advantages of LESS over the traditional laparoscopic approach remain to be fully demonstrated and its disadvantages are widely recognized [1]. Recently, minilaparoscopy and small access retroperitoneoscopy have been rediscovered in an attempt to reduce the invasiveness of standard laparoscopy, improving cosmetic outcome and recovery $[7,8]$.

In addition to equipment, surgeon training remains a critical issue to ensure the safe implementation of any of these less invasive novel techniques [9].

The aim of the present study was to evaluate surgeons' perceptions of different scarless surgical techniques and to determine the relative difficulty in approaching them by assessing their performance in a laboratory setting.

\section{METHODS}

\section{STUDY DESIGN}

The present study was conducted at the Life and Health Sciences Research Institute (ICVS), School of Health Sciences, University of Minho, during the 2nd Minimally Invasive Urological Surgical Week annual course in Braga, Portugal on April 2011. All the participants were invited to enroll in the study and consented to participate. They completed a survey regarding demographic data (age, year of completion of residency, position, practice setting and previous experience).

To begin with, a 3-h training session was undertaken in the dry laboratory. During this session the participants were asked to perform three tasks modelled after the Fundamentals of Laparoscopic Surgery program (http://www.flsprogram.org), including peg transfer, precision cutting, and suturing using intracorporeal knot tying. Thereafter, each trainee performed, under the guidance of a monitor, three porcine nephrectomies using each technique starting with mini-laparoscopy, then LESS and finally, transvaginally, NOTES-assisted laparoscopy.

\section{PROCEDURES}

Domestic pigs, weighing between 25 and $30 \mathrm{~kg}$, were used in the experiment. All the pigs were allowed a minimum period of $72 \mathrm{~h}$ before the procedure to recover from the stress of transportation. Food was withheld for $12 \mathrm{~h}$ before anaesthesia. All procedures were performed under general anaesthesia and mechanical ventilation.

Porcine nephrectomies were performed following standard surgical steps: access, dissection and control of renal vasculture, and kidney dissection. Specimens were not removed at the end of the procedures.

\section{INSTRUMENTATION}

The mini-laparoscopy procedure involved: two 3.5-mm and one 5-mm ports and 3-mm instrumentation (Karl Storz,
Tuttlingen, Germany). A 5-mm scope then a 3-mm paediatric scope were used to allow the insertion of a 5-mm clip applier to control the renal hilum (Fig. 1). Bilateral nephrectomies were performed to minimize the number of pigs killed. Each time, all ports were removed, the abdomen desufflated and access obtained again.

For the LESS procedure, an S-PORTAL ${ }^{\circledR}$ instrument set (Karl Storz) was used, including either the Endocone ${ }^{\mathrm{TM}}$ or $\mathrm{XCone}^{\mathrm{TM}}$ platform, a 5-mm extra length $30^{\circ}$ scope and prebent or regular laparoscopic instruments.

For the NOTES-assisted procedure, two 5-mm trocars allowed the insertion of instruments and one transvaginal port (Karl Storz) was used to accommodate a rigid $10-\mathrm{mm} 30^{\circ}$ scope. The vaginal access was performed under visual guidance after the insertion of a first transabdominal port.

\section{ASSESSMENT}

The following peri-operative data were recorded: time to access the intraperitoneal cavity with successful $\mathrm{CO}_{2}$ insufflation, time to dissect and control the renal hilum, time to complete the procedure, complications, blood loss, and addition of extra ports.

Operating performance was scored by an observer (a monitor) for each working station and by one of two study coordinators by using a 5-item global rating scale (GRS) comprising the categories: operating field view; bimanual dexterity; efficiency; tissue handling; and autonomy. Each category was rated using a scale of 1 to 5 (Appendix 1) as described by Vassiliou et al. [10] for laparoscopic surgery. The final rating represented the mean of the scores from the station monitor and the study coordinator. All of the monitors had extensive experience with laparoscopic 


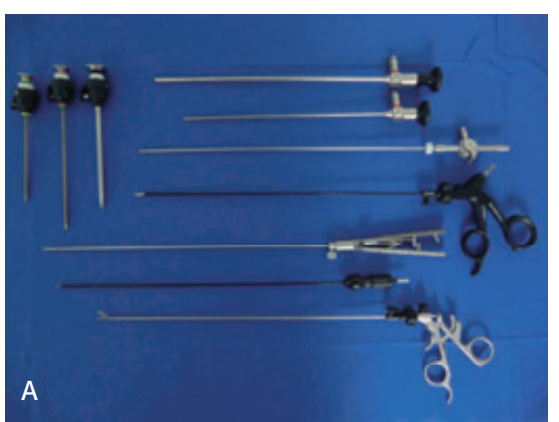

FIG. 1.

Instrumentation used to perform porcine scarless nephrectomies. A, Mini-laparoscopic set. B,

Single-port set. $C$, NOTES-assisted laparoscopy set.
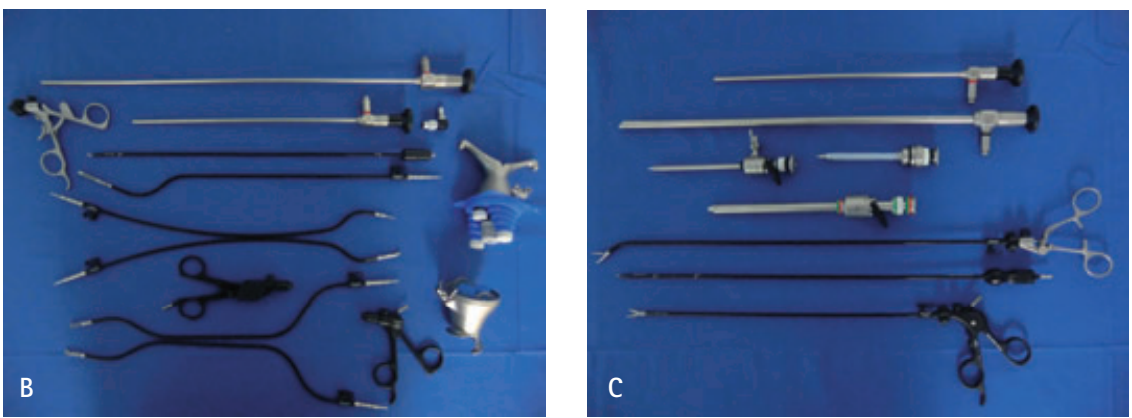

TABLE 1 Porcine nephrectomy: comparative outcomes of scarless techniques

\begin{tabular}{lllll} 
& \multicolumn{3}{l}{$\begin{array}{l}\text { Mini- } \\
\text { laparoscopy, }\end{array}$} & $\begin{array}{l}\text { LESS, } \\
\text { assisted } \\
\text { laparoscopy, }\end{array}$ \\
& $N=14$ & $N=14$ & $N=14$ & $P$ \\
\hline Mean (SD) time to access, min & $10.2(5.3)$ & $8(6.3)$ & $9.9(5.3)$ & 0.59 \\
Mean (SD) time to hilum management, min & $33.4(20.2)$ & $28.2(17.5)$ & $30(15.8)$ & 0.73 \\
Mean (SD) overall procedure time, min & $58.3(25.2)$ & $50.8(20.9)$ & $53(23)$ & 0.70 \\
Complications, $n$ & - & 1 & 1 & \\
Additional port, $n$ & 2 & 1 & 2 & \\
Gas leak, $n$ & - & 3 & - &
\end{tabular}

surgery and were familiarized with the GRS after adequate review of the grading system.

The subjective degree of difficulty was recorded by asking the attendees the following two questions after each procedure: 'How would you score (from 1 = easy to $5=$ Extremely difficult) the degree of difficulty of this nephrectomy?' and 'Compared to what you expected the procedure was... (from $1=$ easier to $5=$ more difficult)!

Data were collected and entered into a database. Results were reviewed, tabulated and analysed using ANOVA multi-analysis. All statistical tests were two-sided and a $P$ value $<0.05$ was considered to indicate statistical significance.

\section{RESULTS}

A total of 14 attendees, whose mean (SD) age was 37.2 (12.5) years, participated. Nine of the 14 were residents/fellows and most of them had limited exposure to laparoscopy. None of the attendees had previous experience in any of these novel scarless techniques.

A total of 42 porcine nephrectomies were successfully performed (14 for each technique). No difference was detected in terms of overall operating time and time to hilum management. Time to gain access was slightly shorter for LESS than for minilaparoscopy or NOTES-assisted laparoscopy, but not significantly shorter. Two complications (vascular injury in both cases) occurred, one in the LESS and one in the NOTES group. Gas leak was detected in three LESS cases (Table 1).

When looking at the performance evaluation scale, despite a better field view for mini-laparoscopy and greater difficulties in bimanual dexterity for LESS, no significant differences were found among the techniques for any of the variables (operating field view: $P=0.52$; bimanual dexterity: $P=0.49$; efficiency: $P=0.77$; tissue handling: $P=0.61$; autonomy: $P=0.2)$ and overall $(P=0.97)$ [Fig. 2]).

Subjective perception of the degree of difficulty trended $(P=0.17)$ in favour of mini-laparoscopy (mean [SD] score 3 [0.8]) compared with LESS (mean [SD] score 3.6 [1]) and NOTES-assisted laparoscopy (mean [SD] score 3.4 [0.7]). No difference was found in terms of surgeons' perceptions as compared with their expectations (mean score $2.5,3$ and 2.5 , respectively; $P=0.34$ ).

\section{DISCUSSION}

Undoubtedly, safety and good outcome are the pillars of any surgical procedure, but patients' increasing favourable perception of scarless surgery has meant that minimally invasive surgery has had to evolve. Bucher et al. [11] sent a questionnaire on laparoscopy, LESS and NOTES to medical and paramedical staff, surgical patients and the general population. Given similar surgical risk, 90\% of the participants preferred a scarless approach over laparoscopy. In another survey, conducted by Omana et al. [12], most healthcare workers and medical students were found to be undecided in their perception of NOTES. The industry has partially responded to the perceived demand for purpose-built instruments and ports with the aim of overcoming the inherent constraints of operating through a very limited working space within novel ergonomic conditions. To learn the techniques and gain familiarity with the equipment, surgeons are enrolling in training courses, most of which use animal models.

The present study was undertaken to improve the understanding of current surgeon perceptions about LESS, NOTESassisted laparoscopy and mini-laparoscopy and the relative difficulty of performing these novel scarless procedures when first 
approaching them. Importantly, the present study is the first to compare the perceptions of surgeons when first facing three different scarless options for performing a porcine nephrectomy and when dealing with the constraints of each technique.

In a recent report, Islam et al. [13] aimed to characterize current surgeon perceptions about LESS and to determine the relative difficulty of performing a simulated LESS task using a multi-port access device. Their study was conducted at the 2009 Society of Gastrointestinal Endoscopic Surgeons Learning Centre and the technical skills and performance of 45 study participants were evaluated using the standardized fundamentals of the laparoscopic surgery peg transfer task, scored according to time and error metrics. The participants completed three repetitions: conventional laparoscopy, LESS with non-articulated instruments, and LESS with articulated instruments. Participants rated their comfort with LESS as $2.0 \pm 1.2$ (5-point scale, $1=$ very uncomfortable). They all indicated a readiness to offer LESS to their patients if appropriately trained. Peg transfer performance was significantly worse for LESS than for laparoscopy (40-65\% performance decline).

Instrument triangulation is one of the cardinal rules of standard laparoscopy that allows effective tissue retraction and dissection during surgery. With LESS, instrument triangulation is more difficult, even with prebent especially designed instrumentation. Certainly, future technological development should focus on improving the instruments' efficiency and ergonomics for an optimum procedure [14]; it has been suggested that LESS is associated with decreased performance and increased surgeon workload compared with standard laparoscopy [15]. In this regard, mini-laparoscopy might represent a favourable option as it combines the ergonomic efficiency of standard laparoscopy with the attractive features of scarless surgery $[7,8]$. It was not surprising that the present study showed that surgeons perceived mini-laparoscopy as technically less difficult.

So far, the transvaginal access appears to be the most applicable for NOTES [2], with an ongoing debate, driven by scepticism and concerns about peritoneal access using the
FIG. 2. Operating performance scored by an observer for each working station by using a 5-item GRS. Each category rated on a 1 to 5 scale. Values presented as mean (SD).
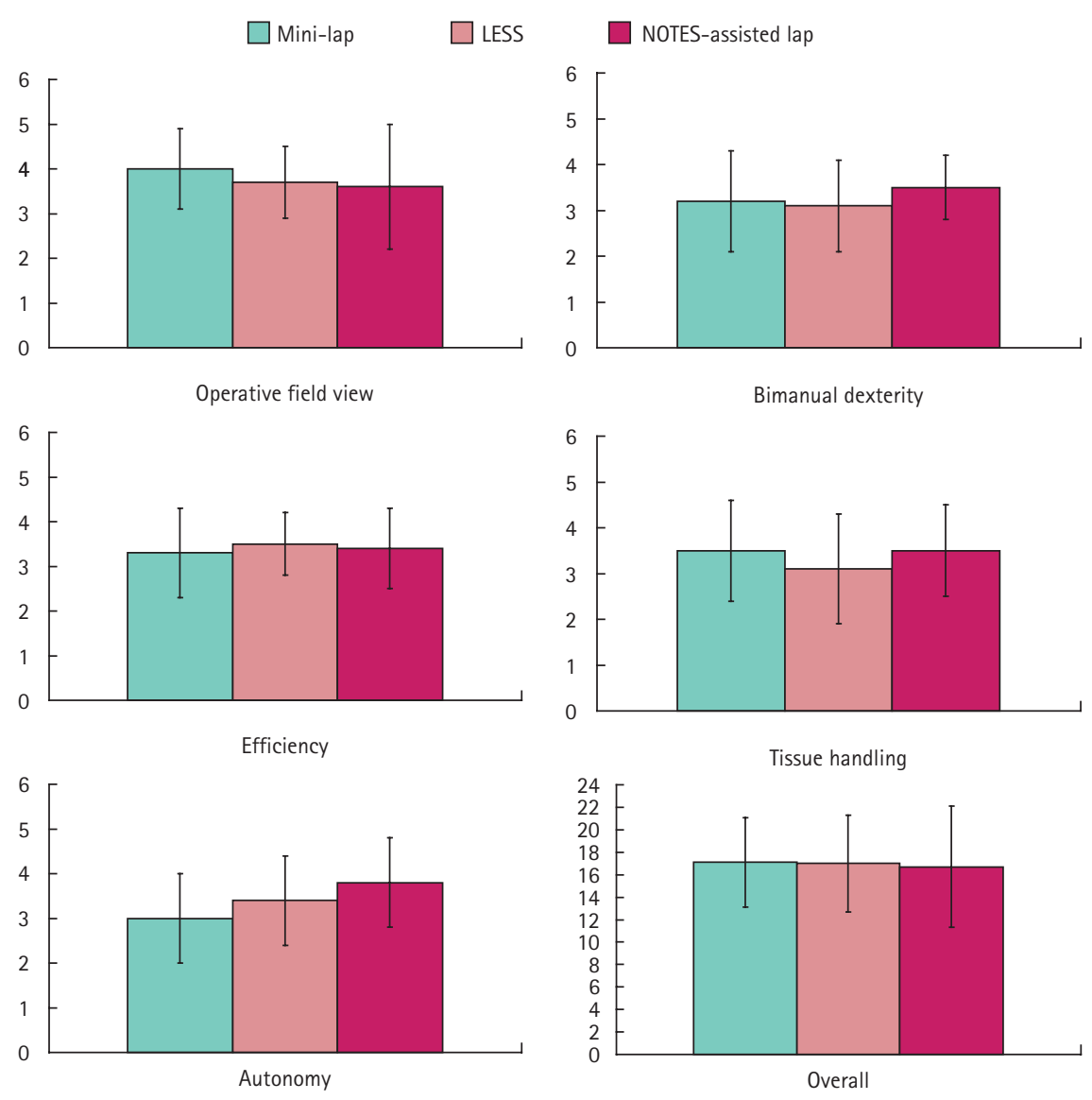

transvaginal route on one side [16] and a considerable public interest and potential receptiveness on the other side [17].

In the present study no difference was detected in terms of peri-operative variables among the three techniques. Not surprisingly, time to gain access was found to be slightly lower for LESS than for mini-laparoscopy or hybrid NOTES. This can be attributed to the fact that for LESS one single-port platform is needed and is placed using the Hassan technique. Nevertheless, gas leak was detected in three LESS cases and this highlights the importance of proper platform placement during a single-port procedure. Only two complications occurred, one in the LESS and the other in the hybrid NOTES group, which might be accounted for by the challenging ergonomics of these techniques. Despite this complication rate not being significantly higher in these groups, it might indicate some safety concerns and support the idea that these novel techniques should be carefully approached.

When looking at the performance evaluation scale, despite a better field view for mini-laparoscopy and higher difficulties in bimanual dexterity for LESS, both not unexpected findings, no significant differences were found among the techniques for any of the GRS items.

No difference was found in terms of surgeons' perceptions compared with their expectations; this was proof that the drawbacks and features of each of the technique are increasingly recognized as the awareness about them grows in the urological community.

Some limitations of the present study need to be acknowledged. The study was not powered and therefore it is likely that the analysis has suffered from the limited sample size. Because of this, no subgroup 
analysis was performed. Regarding study design, lack of randomization should also be noted. We did not consider including a control group of conventional laparoscopy. The tool used for the assessment during the study has been modulated by tools already developed for open surgery and laparoscopy, but it has not been yet validated for LESS or NOTES. It should also be recognized that these surgical procedures are technically easier in the porcine model compared with the human kidney. Another limitation is that the single-port platforms used in the study (Storz Endocone ${ }^{\mathrm{TM}}$ or $\mathrm{XCone}^{\mathrm{TM}}$ ) carry specific features that might have accounted for some of the study findings. Other devices are currently available and have not been used here. Lastly, the GRS was completed by only one observer, which can be regarded as a potential source of bias.

The present study population comprised surgeons, mostly already in training, who were 'novices' in the field of these novel techniques and were mostly without extensive laparoscopic experience. On one hand this limits the generalizability of our findings to other subsets of surgeons with a different background. On the other hand, this can be regarded positively as a signal of interest among urologists, especially young ones, in scarless surgery.

In conclusion, when first approaching new scarless techniques, surgeons tend to perform equally well under expert guidance in the porcine model. Mini-laparoscopy is perceived as less difficult to perform and, for all the techniques, surgeon's perceptions were in line with their expectations.

\section{ACKNOWLEDGEMENTS}

The authors appreciated the support and participation of the MIUSW course attendees for participating in this study and The Research Endoscopic Laboratory at the University of Minho, as well as, the support of Karl Storz, Germany for providing instrumentation used in the study.

\section{CONFLICT OF INTEREST}

None declared.

\section{REFERENCES}

Autorino R, Cadeddu JA, Desai MM

et al. Laparoendoscopic single-site and natural orifice transluminal endoscopic surgery in urology: a critical analysis of the literature. Eur Urol 2011; 59: 26-45

2 Zorron R, Palanivelu C, Galvão Neto

MP et al. International multicenter trial on clinical natural orifice surgery - NOTES IMTN study: preliminary results of 362 patients. Surg Innov 2010; 17 : 142-58

Alcaraz A, Musquera M, Peri L et al. Feasibility of transvaginal natural orifice transluminal endoscopic surgery-assisted living donor nephrectomy: is kidney vaginal delivery the approach of the future? Eur Urol 2011; 59: 1019-25

4 Targarona EM, Gomez C, Rovira R et al. NOTES-assisted transvaginal splenectomy: the next step in the minimally invasive approach to the spleen. Surg Innov 2009; 16: 218-22

5 Kaouk JH, Autorino R, Kim FJ et al. Laparoendoscopic single-site surgery in urology: worldwide multi-institutional analysis of 1076 cases. Eur Urol 2011; 60: 998-1005

6 Pfluke JM, Parker M, Stauffer JA et al. Laparoscopic surgery performed through a single incision: a systematic review of the current literature. J Am Coll Surg 2011; 212: 113-8

7 Porpiglia F, Fiori C, Morra I, Scarpa RM. Transvaginal natural orifice transluminal endoscopic surgery-assisted minilaparoscopic nephrectomy: a step towards scarless surgery. Eur Urol 2011; 60: 862-6

8 Pini G, Goezen AS, Schulze M, Hruza M, Klein J, Rassweiler JJ. Smallincision access retroperitoneoscopic technique (SMART) pyeloplasty in adult patients: comparison of cosmetic and post-operative pain outcomes in a matched-pair analysis with standard retroperitoneoscopy: preliminary report. World J Urol 2011; doi:10.1007/s00345011-0740-x. [Epub ahead of print]

9 Stroup SP, Bazzi W, Derweesh IH. Training for laparoendoscopic single-site surgery and natural orifice transluminal endoscopic surgery. BJU Int 2010; 106: 934-40

10 Vassiliou MC, Feldman LS, Andrew CG et al. A global assessment tool for evaluation of intraoperative laparoscopic skills. Am J Surg 2005; 190: 107-13

11 Bucher P, Pugin F, Ostermann S, Ris F, Chilcott M, Morel P. Population perception of surgical safety and body image trauma: a plea for scarless surgery? Surg Endosc 2011; 25: 408-15

12 Omana JJ, Mistry S, Herron D, Kini S. Perception of NOTES among health care workers and medical students. Surg Innov 2010; 17: 63-8

13 Islam A, Castellvi A0, Tesfay ST et al. Early surgeon impressions and technical difficulty associated with

laparoendoscopic single-site surgery: a Society of American Gastrointestinal and Endoscopic Surgeons learning center study. Surg Endosc 2011; 25: 2597603

14 Haber GP, Autorino R, Laydner $\mathrm{H}$ et al. SPIDER Surgical system for urologic procedures with laparoendoscopic single-site surgery: from initial laboratory experience to first clinical application. Eur Urol 2012; 61: 41522

15 Montero PN, Acker CE, Heniford BT, Stefanidis D. Single incision laparoscopic surgery (SILS) is associated with poorer performance and increased surgeon workload compared with standard laparoscopy. Am Surg 2011; 77: 73-7

16 Strickland AD, Norwood MG, BehniaWillison $\mathrm{F}$ et al. Transvaginal natural orifice transluminal endoscopic surgery (NOTES): a survey of women's views on a new technique. Surg Endosc 2010; 24: 2424-31

17 Peterson CY, Ramamoorthy S, Andrews $B$ et al. Women's positive perception of transvaginal NOTES surgery. Surg Endosc 2009; 3: 1770-4

Correspondence: Riccardo Autorino, MD, $\mathrm{PhD}$, Assistant Professor, Second University of Naples, Piazza Miraglia 2, CAP 80138, Naples, Italy. e-mail: ricautor@tin.it

Abbreviations: LESS, laparoendoscopic single-site surgery; NOTES, natural orifice transluminal endoscopic surgery; GRS, global rating scale. 
AUTORINO ET AL.

APPENDIX 1

GLOBAL RATING SCALE

\begin{tabular}{|c|c|c|c|c|c|}
\hline & 1 & 2 & 3 & 4 & 5 \\
\hline Operating field view & Inadequate & & $\begin{array}{l}\text { Requiring several adjustments, but } \\
\text { adequate }\end{array}$ & & Optimum \\
\hline Bimanual dexterity & $\begin{array}{l}\text { Uses only one hand, ignores non-dominant } \\
\text { hand, poor co-ordination between } \\
\text { hands }\end{array}$ & & $\begin{array}{l}\text { Uses both hands, but does not } \\
\text { optimize interaction between hands }\end{array}$ & & $\begin{array}{l}\text { Expertly uses both hands in a } \\
\text { complimentary manner to provide } \\
\text { optimum exposure }\end{array}$ \\
\hline Efficiency & No progression in surgical steps & & $\begin{array}{l}\text { Slow, but planned movements are } \\
\text { reasonably organized }\end{array}$ & & $\begin{array}{l}\text { Efficient and safe conduct, procedure } \\
\text { performed in adequate time }\end{array}$ \\
\hline Tissue handling & $\begin{array}{l}\text { Rough movements, tears tissue, injures } \\
\text { adjacent structures, poor grasper control }\end{array}$ & & $\begin{array}{l}\text { Handles tissues reasonably well, } \\
\text { minor trauma to adjacent tissue }\end{array}$ & & $\begin{array}{l}\text { Handles tissues well, applies } \\
\text { appropriate traction, negligible } \\
\text { injury to adjacent structures }\end{array}$ \\
\hline Autonomy & $\begin{array}{l}\text { Unable to complete entire task, even with } \\
\text { manual guidance }\end{array}$ & & $\begin{array}{l}\text { Able to complete task safely with } \\
\text { moderate verbal guidance }\end{array}$ & & $\begin{array}{l}\text { Able to complete task independently } \\
\text { with minimal guidance }\end{array}$ \\
\hline
\end{tabular}

